\title{
Lagoa do Portinho em Parnaíba, Piauí, Brasil: Avaliação da infraestrutura e atrativos turísticos
}

Lagoa do Portinho in Parnaíba, Piaui, Brazil: Evaluation of the infraestructure and tourist attractions

\author{
Keline Medeiros de Araujo', Deyse Cristina Castro de Oliveira², Juliana Rodrigues Rocha ${ }^{3}$, Jefferson Almei- \\ da Rocha ${ }^{4}$, Jurandy do Nascimento Silva ${ }^{5}$, Stefan Vilges de Oliveira ${ }^{6}$ \\ 1, 6 Universidade de Brasília, Brasília, Brasil. \\ 2,4 Universidade Federal do Piauí, Teresina, Brasil. \\ ${ }^{3}$ Faculdade de Educação de Bacabal, Bacabal, Brasil. \\ ${ }^{5}$ Instituto Federal de Educação, Ciência e Tecnologia do Piauí, Teresina, Brasil.
}

\begin{abstract}
Resumo
O turismo pode ser considerado hoje como sendo a maior indústria do planeta e o ecoturismo é um ramo dessa indústria que cresce cerca de $20 \%$ ao ano. O Brasil é reconhecido por apresentar um grande número de atrativos para todos os perfis de ecoturistas e condições para as mais diversas formas de atividades ecoturísticas. Nesse contexto, existem poucos estudos sobre a Lagoa do Portinho, no estado do Piauí, um ponto turístico bastante visitado na região do Delta do Parnaíba. O objetivo deste trabalho foi avaliar a infraestrutura, atrativos turísticos e identificar os impactos positivos e negativos do turismo. Foi desenvolvido um estudo descritivo de abrangência local, onde a busca de informações se deu por questionamentos e observações. Os resultados mostraram que a região apresenta uma boa infraestrutura 54,28\% e 42,85\% dos entrevistados relataram considerar boa a oferta de atrativos turísticos. No entanto, 38,57\% relataram a limpeza local e a destinação do lixo como regular. Assim é possível inferir que a região está apta para recepção de turistas, pois oferece boas opções de lazer e apresenta uma infraestrutura satisfatória para acolhimento dos mesmos, porem investimentos buscando promover a destinação correta de resíduos deveriam ser implantados no local.
\end{abstract}

Palavras-chave: Turismo, ecoturismo, preservação.

\begin{abstract}
Tourism may be regarded today as the biggest industry of the world and ecotourism is a branch of this industry that grows around $20 \%$ per year. Brazil is known for providing the highest number of attractions for all profiles of ecotourist and conditions for the most diverse forms of ecotourism. In this context there are few studies on Lagoa do Portinho in the Parnaiba Delta, in the state of Piauí. The objective of this study was to evalute the infrastructure, touristics attractions and identify positive and negative impacts on local tourism. A descriptive study of local resources was developed, where the seek for details was made by questioning and remarks. The results showed that the region has good infrastructure $54.28 \%$ and $42.85 \%$ of those surveyed reported seeing as good the offer of tourists attractions. However, $38.57 \%$ reported that the cleaning and disposing of garbage was merely regular. Therefore we concluded that the region is able to receiving tourists, it offers good options for leisure and satisfactory infrastructure. However is required investiments for proper disposal of garbage.
\end{abstract}

Keywords: Tourism, ecotourism, preservation. 


\section{INTRODUÇÃO}

O turismo compreende as inúmeras atividades que exigem deslocamentos de pessoas com variadas finalidades, tais como, divertimento, visitas a locais atrativos, lazer, movimentos culturais, etc. É considerado um dos maiores movimentos de migração no processo histórico do mundo e apresenta um crescimento contínuo (CUNHA, 2001). O ecoturismo é um segmento que mais cresce dentro da área do turismo. É diferente, ecológico, ou seja, preserva a natureza e ao mesmo tempo distrai e melhora a qualidade de vida dos que o praticam (SILVA, 2004). Atrai uma infinidade de pessoas que gostam do contato direto com a natureza, de fazer longas caminhadas e admirar a beleza de uma área conservada. Porém, se realizado de forma irresponsável pode ocasionar uma série de impactos negativos no ambiente (SILVA, 2004).

O termo impacto é caracterizado por uma alteração nas propriedades físicas, químicas e biológicas do meio ambiente, causada por qualquer forma de matéria ou energia advinda de atividades antrópicas ou não, que modifiquem direta ou indiretamente de forma positiva ou negativa o meio. Sendo assim o ecoturismo deve ser planejado ou gerido de forma sustentável, levando em conta a proteção e utilização econômica adequada do ambiente natural e humano (OLIVEIRA, 2007).

Nas considerações a respeito da oferta turística, os aspectos naturais e geográficos das regiões assumem um papel importante como elemento de identificação e caracterização na definição da própria natureza do produto, ou seja, a geografia local colabora com a diversidade de atrativos locais. Dentre diversas características físicas e os vários elementos ornamentais das paisagens consideradas ofertas turísticas naturais, encontram-se: Planícies, montanhas, grutas, nascentes de águas, riachos, cachoeiras, ilhas, rios, lagos e lagoas (ANDRADE, 2001). São perceptíveis que, além de uma cultura diversificada, os elementos naturais são ferramentas imprescindíveis para o desenvolvimento turístico do Brasil.

O Piauí está se inserindo cada vez mais no contexto do turismo atual. O estado tem uma economia baseada na agricultura, no comércio, no extrativismo e na pecuária, suas principais fontes de renda. Desenvolve também atividade industrial, formada por micro e pequenas empresas. O turismo tem sido hoje uma das principais metas do governo do Estado. Através das belezas naturais e culturais, da diversidade e hospitalidade de seu povo, vem-se desenvolvendo segmentos turísticos para todos os perfis e gostos. Destaca-se no turismo o sol e o mar no Delta do Parnaíba, envolvido por $66 \mathrm{~km}$ de litoral com belas praias. Além disso, o turismo de aventura na cidade de Pedro II, o turismo histórico cultural em São Raimundo Nonato e suas "Sete Cidades", o turismo de eventos e negócios em Teresina e uma infinidade de atrativos passíveis de visitação (COSTA, 2010).

Neste contexto, insere-se a Lagoa do Portinho, a qual é um dos locais turísticos mais frequentados do litoral piauiense, além de ser uma área de lazer muito visitada pela população das cidades de Luís Correia e Parnaíba.

De acordo com Ruschmann (1997) os impactos do turismo referem-se a uma gama de modificações ou a sequência de eventos provocados pelo processo de desenvolvimento turístico nas localidades receptoras. Eles têm natureza, intensidade, e categorias diversas. Entre os impactos negativos mais comuns pode-se citar: destruição das espécies (extinção de plantas e animais nativos), degradação dos habitat, do solo, poluição das águas, do ar e etc. (COSTA, 2010).

Desta forma, com o aumento do uso destas áreas para fins de recreação e lazer, é importante buscar técnicas adequadas para avaliar, aplicar medidas atenuadoras de proteção e propagar informações adequadas sobre a relação entre ecologia e lazer (MIDAGLIA, 1999). A educação ambiental é um importante subsídio na preservação ambiental, pois a mobilização pública através de sua conscientização pode contribuir para a efetiva execução de medidas diminuidoras do impacto antrópico (PERINOTTO, 2008).

Contudo o aumento da demanda por atividades desenvolvidas junto à natureza, acompanhado da exploração desordenada e irresponsável das atividades ecoturísticas vem causando a massificação dessa modalidade, tendendo a comprometer seriamente o desenvolvimento sustentável das regiões e impactar irreversivelmente os ambientes naturais e as comunidades locais.

Assim essa pesquisa teve como objetivo reconhecer a infraestrutura estabelecida na Lagoa do Portinho, os atrativos turísticos e identificar os impactos positivos e negativos do turismo local e sugerir medidas de proteção ambiental para a região. 


\section{MATERIAIS E MÉTODOS}

\section{I CaracterizaÇão da Área de estudo}

A lagoa do Portinho separa os municípios de Parnaíba de Luís Correia, ficando a $15 \mathrm{~km}$ de Parnaíba. Está localizada nas coordenadas $2^{\circ} 55^{\prime} 43.2^{\prime \prime}$ Sul e $41^{\circ} 40^{\prime} 30.7^{\prime \prime}$ Oeste, a $345 \mathrm{~km}$ da capital Teresina-PI. Possui uma área de 05 quilômetros quadrados e estende-se por 09 quilômetros, no sentido Norte/Sul (Figura 01). O acesso é feito pela BR - 343 para Luís Correia. Atualmente esse ponto turístico e gerenciado pela secretária estadual de turismo do Estado do Piauí. Trata-se de uma lagoa de várzea formada naturalmente no leito do Rio Portinho, próxima a sua foz. Sua mata ciliar recobre atualmente cerca de $50 \%$ da margem e sua vegetação típica é a caatinga (UNIVERSIDADE FEDERAL DO PIAUÍ, 2007).

\subsection{COLETA DE INFORMAÇÕES}

A metodologia consistiu em um estudo descritivo de abrangência local, com base em dados obtidos no levantamento de informações com os moradores e os turistas da região. O principal foco retrata os problemas e as potencialidades turísticas da Lagoa do Portinho. As observações registradas in loco foram obtidas por meio de equipamentos fotográficos.

A coleta de informações se respaldou em Cavalcante e Maciel (2008), que propõem uma análise da percepção baseada em questionamento e na observação.

Foram considerados no estudo frequentadores da lagoa do portinho, sendo entrevistados 70 indivíduos escolhidos aleatoriamente em uma amostragem de conveniência em pontos ao longo da margem da lagoa (Figura 01).

A coleta de dados foi realizada utilizando um questionário semi-estrurado com variáveis descritivas categorizadas relacionadas à infraestrutura do local e atrativos turísticos.

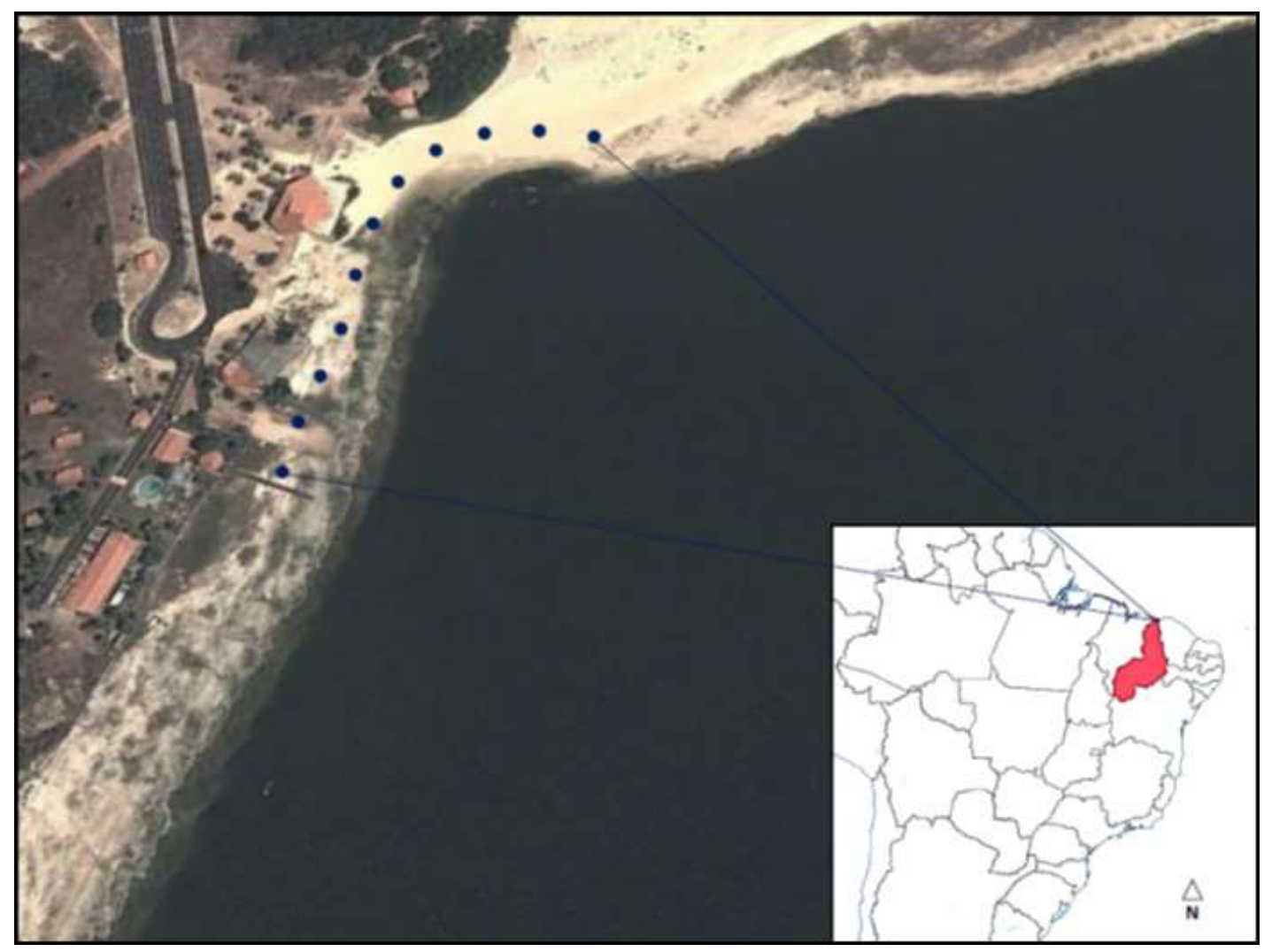

Figura 01. Vista aérea da lagoa do Portinho, Piauí, Brasil (Google Earth). Círculos azuis delimitando área onde foi realizado o estudo.

Para a infraestrutura avaliou-se: hospedagem, bares, restaurantes e destinação de resíduos. E para os atrativos turísticos: belezas naturais e esportes aquáticos. 
O período da analise compreendeu o mês de fevereiro de 2013, durante o carnaval, considerada época de alta temporada na região, em que ocorre maior frequência de visitantes.

As repostas dos questionários são apresentadas por meio de proporções. Para os cálculos das proporções, utilizamos no numerador a somatória das respostas dos entrevistados e no denominador se considerou a população entrevistada ou que tenha respondido a respectiva pergunta. Os cálculos foram feitos através do software Microsoft Office Excel 2007.

\section{RESULTADOS E DISCUSSÃO}

Os dados levantados durante a pesquisa realizada sobre a infraestrutura demonstraram que $54,28 \%$ (38-70) dos participantes consideraram boa (Tabela 01$)$.

Tabela 01 - Avaliação da infraestrutura da Lagoa do Portinho, Piauí, Brasil.

\begin{tabular}{lcc}
\hline $\begin{array}{c}\text { Categoria de } \\
\text { avaliação }\end{array}$ & Quantidade & \% Porcentagem \\
\hline Ótimo & 39 & 55,71 \\
Bom & 30 & 42,85 \\
Regular & 1 & 1,42 \\
Ruim & 0 & 0 \\
\hline Total & 70 & 100 \\
\hline
\end{tabular}

Segundo Midaglia (1999) alguns ambientes naturais têm sido enormemente valorizados pela atividade turística e proporcionam de certa forma, um contato mais direto com a natureza. A lagoa do Portinho é um local de lazer e entretenimento, apresenta uma infraestrutura receptiva oferecendo bares e opções de hospedagem, alimentação, entretenimento, restaurantes, espaços para shows, estacionamentos e atracadouros para lanchas (MINISTÉRIO DO MEIO AMBIENTE, 2013).

Foi observado que as pessoas que realizam ecoturismo ou turismo ecológico na Lagoa do Portinho podem desfrutar de uma série de atrativos que o local oferece, tais como belas paisagens, banana boat, jet ski, windsurf, locais propícios para caminhadas e ainda a própria lagoa que pode ser utilizada para banho. Aos domingos e feriados, os restaurantes que ficam à margem da Lagoa promovem shows. A figura 2 mostra uma das opções de lazer de fácil acesso, a conhecida banana boat bem como um bar/ restaurante para recepção dos turistas.

Em relação aos atrativos turísticos, verificou-se que 55,71\% (39-70) dos visitantes entrevistados consideraram ótimos (Tabela 02). Para eles os pontos positivos do turismo na Lagoa do Portinho estão relacionados à possibilidade de usufruir das belezas naturais.

A presença constante de visitantes na lagoa do Portinho chama atenção para o impacto que a utilização não planejada pode causar a este ambiente. As pessoas estão inseridas nesse contexto, porque além de proporcionarem benefícios para a região visitada também podem causar danos ao local através de ações equivocadas (LAGOA DO PORTINHO, 2013).

Sousa et al. (2012) que realizaram um estudo sobre a percepção ambiental no turismo na Cachoeira do Urubu, Estado do Piauí, em período de carnaval, observaram resultados compatíveis aos do presente estudo. Verificando que $82,5 \%$ dos pesquisados, consideram a limpeza como regular a péssima. Esse quadro é aumentado em períodos de grande movimentação, sendo compatível aos dados encontrados na Lagoa do Portinho.

Ribeiro et al. (2012) abordaram em seu trabalho os impactos sociais no município de Mãe d'Água, 
Tabela 02. Distribuição da opinião dos visitantes sobre atrativos turísticos da Lagoa do Portinho, Piauí, Brasil.

\begin{tabular}{lcc}
\hline $\begin{array}{c}\text { Categoria de } \\
\text { avaliação }\end{array}$ & Quantidade & \% Porcentagem \\
\hline Ótimo & 39 & 55,71 \\
Bom & 30 & 42,85 \\
Regular & 1 & 1,42 \\
Ruim & 0 & 0 \\
\hline Total & 70 & 100 \\
\hline
\end{tabular}

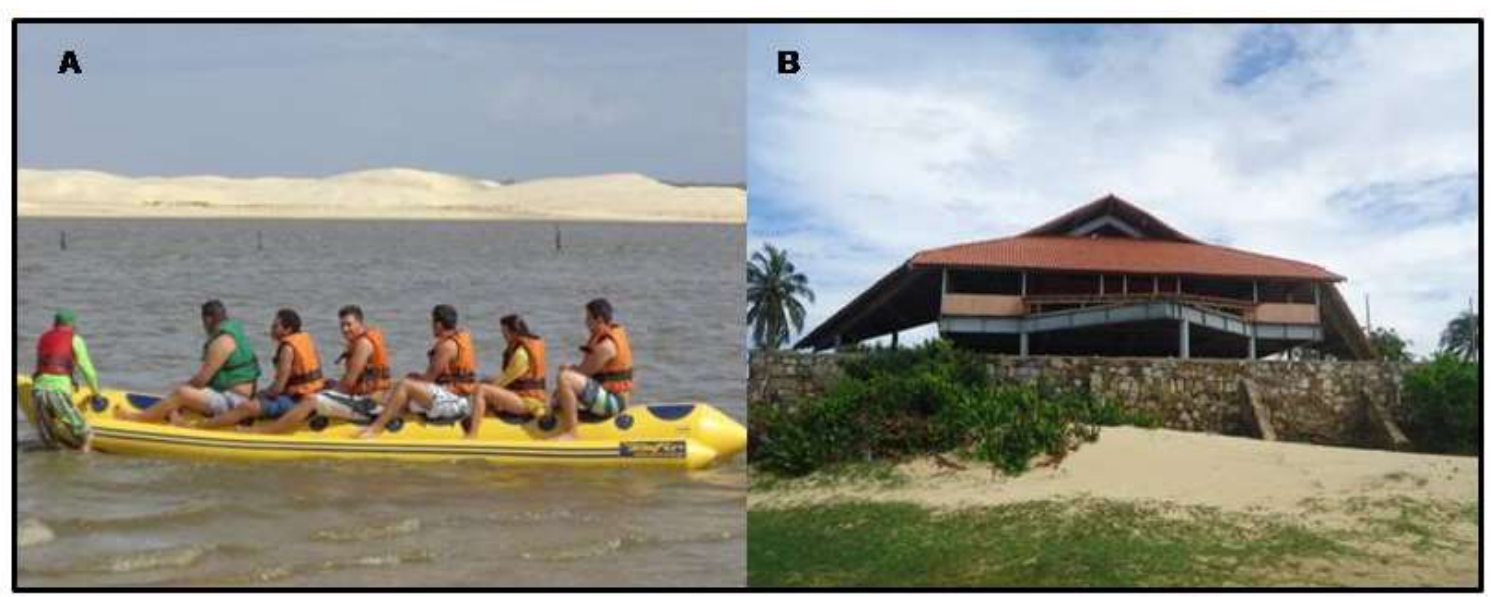

Figura 02. Percepção do entrevistador sobre aspectos relacionados à atrativos turísticos/infraestrutura. Em (A) Passeio turístico em banana boat, em (B) restaurante da região.

Estado da Paraíba, decorrentes do aumento da atividade turística. Foi visto que, de uma forma geral, os visitantes não conservam a região, sendo o lixo um dos fatores agravantes.

Segundo Mucelin e Bellini (2008) a problemática ambiental gerada pelo lixo é de difícil solução e a maior parte das cidades brasileiras apresenta um serviço de coleta que não prevê a separação dos resíduos na fonte. Materiais sem utilidade se amontoam indiscriminada e desordenadamente, muitas vezes em locais indevidos como lotes baldios, margens de estradas, fundos de vale e margens de lagos e rios (OLIVEIRA-JUNIOR et al. 2013).

A região da Lagoa do Portinho conta com um sistema de coleta de lixo que ocorre apenas duas vezes por semana, isso compromete o potencial turístico do local, uma vez que esse lixo acumulado pode atrair animais e contribuir para a formação de um conjunto de imagens negativas para a Lagoa.

Durante o período em que ocorreu a pesquisa, foi observada na estrada de acesso à Lagoa do Portinho e na área frequentada pelos turistas a presença de lixo proveniente do funcionamento dos bares localizados às margens da lagoa (Figura 03).

Quando questionados sobre a limpeza do local, 38,57\% (27-70) dos entrevistados consideraram regular a presença do lixo (Tabela 03).

Apesar dos impactos negativos causados pela visitação dos turistas e utilização dos recursos locais, vale ressaltar que os mesmos contribuem para o crescimento econômico da região. Nesse contexto, o turismo não pode ser visto como responsável direto pelos impactos negativos e pela degradação do 
Tabela 03. Opinião dos visitantes sobre a limpeza da Lagoa do Portinho, Piauí, Brasil.

\begin{tabular}{ccc}
\hline $\begin{array}{c}\text { Categoria de } \\
\text { avaliação }\end{array}$ & Quantidade & \% Porcentagem \\
\hline Ótimo & 10 & 14,28 \\
Bom & 21 & 30,00 \\
Regular & 27 & 38,57 \\
Ruim & 12 & 17,14 \\
\hline Total & 70 & 100 \\
\hline
\end{tabular}

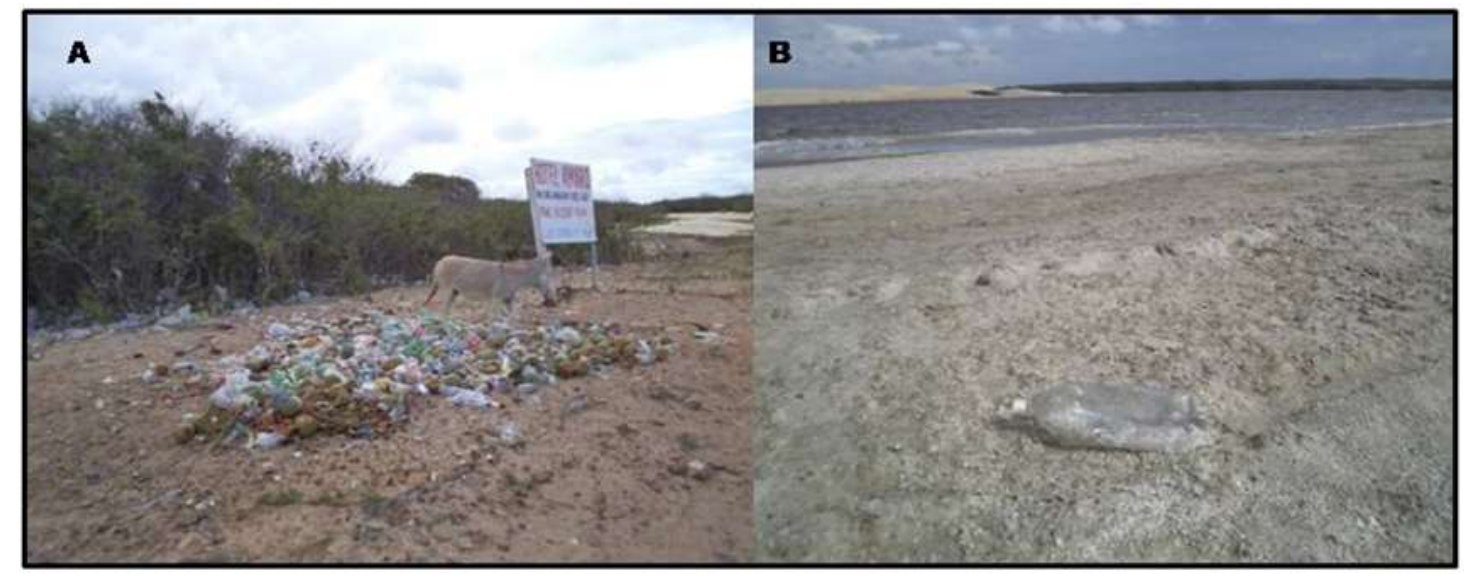

Figura 03. Observação do entrevistador sobre aspectos relacionados à infraestrutura. Em (A) Acúmulo de lixo na entrada da Lagoa do Portinho, Piauí, Brasil, em (B) garrafas pets na região visitada pelos turistas.

ambiente, uma vez que toda atividade que utilize dos recursos naturais poderão poluir e até mesmo causar mudanças no meio em que se insere.

Medidas para conservação deverão ser adotadas para preservação, manutenção e a utilização sustentável dos recursos locais.

Para Silva (2004) a educação ambiental merece destaque sendo instrumento indispensável no ambiente escolar para interagir com as comunidades locais, por meio de reuniões, campanhas educativas e mutirões, tais estratégias se mostram primordiais para a preservação do meio ambiente. Silva (2004) sugere ainda algumas medidas de correção a fim de diminuir os impactos ambientais em áreas que recebem turistas. Recomenda-se a utilização de recipientes apropriados para descarte de lixo, limitar número de visitantes por área, conduzir campanhas de conscientização permanentes na mídia, distribuir materiais educativos. Essas estratégias podem ajudar a manter o ambiente ecologicamente seguro e tornar o turismo mais agradável e prazeroso.

\section{CONCLUSÃO}

Por meio dessa pesquisa foi possível concluir que a infraestrutura presente na região da Lagoa do Portinho atende as expectativas dos entrevistados, e que os atrativos turísticos locais são considerados satisfatórios.

Por meio das observações e dos questionamentos aos turistas, o lixo e sua destinação correta, 
foi apontado como principal problema de infraestrutura da área.

Em vista disto, foram sugeridas algumas alternativas para assegurar que o ambiente se mantenha preservado. No entanto, é notória a necessidade de uma conscientização e sensibilização, por parte da sociedade, das questões ambientais, para que esse lugar se mantenha preservado e favorável para atividades turísticas. Os visitantes e a comunidade local precisam entender a real importância da preservação do patrimônio ambiental, tanto para as gerações futuras como para o próprio crescimento econômico local.

\section{AGRADECIMENTOS}

Os autores agradecem a participação dos turistas na entrevista realizada na Lagoa do Portinho, bem como aos moradores da região que se dispuseram a responder os questionamentos para que a pesquisa pudesse ser concluída com êxito.

\section{REFERÊNCIAS}

ANDRADE, J.V. Turismo: Fundamentos e dimensões. $8^{a}$ edição, Editora Ática, São Paulo, 216p, 2001.

CAVALCANTE, S.; MACIEL, R. H. Métodos de avaliação da percepção ambiental. In: PINHEIRO, J. Q.; GÜNTHER, H. (Orgs.). Métodos de pesquisa nos estudos pessoa-ambiente. São Paulo: Casa do Psicológico, $181 p, 2008$.

COSTA, J.K.B. O turismo sustentável e a utilização de espaços naturais: Estudo de caso do parque João Mendes Olímpio de Melo (Parque da Cidade) em Teresina-PI. Interciências. v. 2, n.2, 2010.

CUNHA, L. Introdução ao Turismo. Editora Verbo. Lisboa, 448p, 2001.

LAGOA DO PORTINHO. Vamos fazer um passeio em Parnaíba? Disponível: http://biologiauapiphb.blogspot.com.br/2011/12/lagoa-do-portinho.html. Acessado em: 22 de maio de 2013.

MIDAGLIA, C.L. Turismo e meio ambiente no litoral paulista: Dinâmica da balneabilidade nas praias. In: Lemos, A. Turismo: impactos socioambientais. Editora Hucitec, São Paulo, p.32-56, 1999.

MINISTÉRIO DO MEIO AMBIENTE. Disponível em www.mma.gov.br, Acessado em: 22 de maio de 2013.

MUCELIN, C.A.; BELLINI, M. Lixo e impactos ambientais perceptíveis no ecossistema urbano. Sociedade e Natureza. v. 20, n.1, 2008.

OLIVEIRA, E. S. Impactos socioambientais e econômicos do turismo e suas repercussões no desenvolvimento local: o caso do Município de Itacaré-Ba. Revista Internacional de desenvolvimento local. v. 8, n.2, p.193-202, 2007.

OLIVEIRA-JUNIOR, E. S.; BUHLER, B. F.; MUNIZ, C. C.; FURLAN, A. O. Córregos urbanos do município de Cáceres-MT, Brasil: um olhar para a conservação. Revista Eletrônica em Gestão, Educação e Tecnologia Ambiental. v. 17, n. 17, p. 3268- 3274, 2013. http://dx.doi.org/10. 5902/2236117010431

PERINOTTO, A.R.C. Turismo Pedagógico: uma ferramenta para a educação ambiental. Caderno virtual de Turismo. v. 8, n.1., 2008.

RIBEIRO, W.M.; LEITE, M.J.H.; GOMES, A.D.V.; SILVA, F.G.; FARIAS JR, J.A.; FARIAS, A.E.S. Avaliação de impacto social em área turística: cachoeira dos batentes no município de Mãe d'Água-PB. Scientia Plena. v.8, n.4, 2012. 
RUSCHMANN, D. Turismo e planejamento sustentável: A proteção do meio ambiente. $14^{a}$ edição, Editora Papirus, São Paulo, 197p, 1997.

SILVA, M.F.L. O Ecoturismo no Delta do Parnaíba- PI e entorno: turismo e sustentabilidade. Monografia (Especialização em Turismo e Hospitalidade). Centro de Excelência em Turismo. Universidade de Brasília, 93p, 2004.

SOUSA, A.R.P. DE; ARAÚJO, J.L.L.; LOPES, W.G.R. Percepção ambiental no turismo do Parque Ecológico Cachoeira do Urubu nos municípios de Esperantina e Batalha no estado do Piauí. Raega, v.24, p.69-91, 2012

UNIVERSIDADE FEDERAL DO PIAUÍ. Araripe, H.G.A.; Sales, L.T.; Santiago, A.P. Ataque de peixes a banhistas na Lagoa do Portinho Parnaíba-PI, 2007. Disponível: http://www.proparnaiba.com/sites/default/ files/lagoa_do_portinho11.pdf. Acessado em: 13 de março de 2014. 